\title{
Evaluation of Plasmodium falciparum K13 gene polymorphism and susceptibility to dihydroartemisinin in an endemic area
}

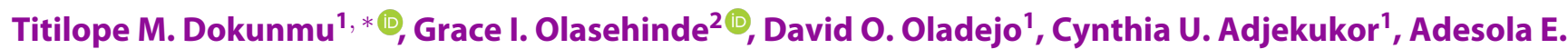 \\ Akinbohun ${ }^{1}$, Olabode A. Onileere ${ }^{2}$, Chisom J. Eze ${ }^{1}$, Grace S. Jir ${ }^{1}$
}

${ }^{I}$ Department of Biochemistry, Covenant University, Km 10 Idiroko road, Canaanland, Ota, 23401, Nigeria

${ }^{2}$ Biological Sciences Department, Covenant University, Nigeria

\section{Correspondence}

Titilope M. Dokunmu, Department of Biochemistry, Covenant University, Km 10 Idiroko road, Canaanland, Ota, 23401, Nigeria

Email: titi-

lope.dokunmu@covenantuniversity.edu.ng

History

- Received: 25 June 2018

- Accepted: 31 August 2018

- Published: 24 September 2018

DOI :10.15419/bmrat.v5i9.474

\section{Check for updates}

\section{Copyright}

( ) Biomedpress. This is an openaccess article distributed under the terms of the Creative Commons Attribution 4.0 International license.

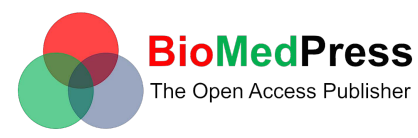

\begin{abstract}
Introduction: Plasmodium falciparum has developed resistance to artemisinin drugs in Southeast Asia, and its reduced sensitivity has been reported in other regions. This study aims to determine parasite susceptibility to the bioactive form of artemisinin derivatives- dihydroartemisinin (DHA)-, and to detect the K13 polymorphism in isolates from an endemic area of Nigeria. Methods: Ex-vivo response in 55 parasites isolates obtained from malaria-positive patients were exposed to pulseDHA concentration and cultured for 66 hours ex-vivo. Parasite ring stage survival (RSA ex-vivo) relative to unexposed matched control was determined by microscopy, and parasite growth was compared using Mann-Whitney $U$-test at a significance level of $P<0.05$. The Kelch propeller gene was amplified using specific primers, then sequenced and analyzed for single nucleotide polymorphisms (SNPs), which were compared to reference PF3D7_1343700. Results: Overall, 151 of 375 (40.2\%) individuals were positive during the study period. In 55 selected isolates, there was increased growth in unexposed wells but growth was inhibited in DHA-exposed wells, with growth rate between 14.9 $96.7 \%$. The mean $\mathrm{RSA}_{\text {ex-vivo }}$ value was $0.18 \pm 0.09 \%, 95 \% \mathrm{Cl}(0.15-0.20)$. There was no significant mutation of the K13 gene in the parasite isolates evaluated. Conclusions: Plasmodium falciparum isolates from this endemic area show high sensitivity to dihydroartemisinin ex-vivo, with no mutations conferring artemisinin resistance. Continuous monitoring of parasite susceptibility to artemisinin combination drugs should be intensified to reduce chances of artemisinin resistance in endemic areas.
\end{abstract}

Key words: Artemisinin resistance, Kelch propeller gene, Nigeria, Plasmodium falciparum, RSA

\section{INTRODUCTION}

Artemisinin combination treatments (ACTs) have been widely adopted for the treatment of falciparum malaria control globally ${ }^{1}$. However, in some areas in Southeast (SE) Asia, artemisinin-resistant parasites have emerged ${ }^{2-8}$. In highly endemic African countries, it is essential to constantly monitor susceptibility to artemisinin derivatives and ACTs. In Asia, an emergence of artemisinin-resistant parasites have been confirmed with declining sensitivity in-vitro and in-vivo to artemisinin ${ }^{9-12}$, whereby the parasites remain in quiescent or dormant state, and exhibit phenotypic delayed clearance from peripheral blood ${ }^{13-15}$. These parasites have ring stage survival value $>1$, delayed parasite clearance in-vivo, and polymorphisms of the Kelch propeller (K13) gene that confers resistance to artemisinin drugs ${ }^{6-8,14-16}$. These form the basis for detection and confirmation of parasite resistance to artemisinin drugs globally ${ }^{17}$.

Susceptibility of Plasmodium falciparum to nonartemisinin drugs can be determined by comparing $\mathrm{IC}_{50}$ values with a sensitive strain. However, this method fails to correctly predict parasite susceptibility to artemisinin ${ }^{3}$. Determining the survival of the ring stage parasite in-vitro or ex-vivo is a more robust method for detection of susceptibility to artemisinins ${ }^{16}$. In Nigeria, reports of in-vitro declining response to artemisinin and its association with mutations of transporter genes have been previously reported $^{18,19}$. Yet, there are few studies that assess in-vivo or ex-vivo susceptibility of $P$. falciparum to artemisinin and assess the K13 gene polymorphism in the parasites; one study has reported no polymorphisms of the K13 gene in Nigerian isolates ${ }^{20}$. The World Health Organization (WHO) recommends continuous monitoring of responses to ACTs to curb the spread of resistance to other areas ${ }^{17}$. Therefore, the aim of this study was to evaluate the ring stage survival of $P$. falciparum isolates and the K13 gene polymorphism in a high malaria hotspot in Africa. 


\section{METHODS}

\section{Study population}

The study population was a cohort from a larger population of 375 individuals who were part of an ongoing community health survey in Ota, Nigeria, evaluating malaria prevalence and markers of antimalarial drug resistance in an endemic area. Data from this population has been published in part previously ${ }^{21}$. The sub-population included for the current study were children and adults (aged $>6$ months) with $P$. falciparum mono-infection and parasitemia between $1-5 \%$ as detectable by microscopy. Persons with base-line parasitemia $<1 \%$ were excluded from this eval-uation. Informed consent was sought from the par-ticipants and ethical approval was sought from local authorities and the Covenant Health Research Ethics Committee, Nigeria.

\section{Sample collection}

Venous blood from 55 malaria positive subjects who met the inclusion criteria was taken aseptically into EDTA bottles, and blood was spotted on slides for thin and thick film microscopy to confirm $P$. falciparum mono-infection. The samples were transported to the laboratory on ice for further processing.

\section{Laboratory analysis}

Blood samples were washed twice in RPMI 1640 medium (Sigma Aldrich, USA), centrifuged at 2500 $\mathrm{x} g$ and made up to $1.5 \%$ hematocrit and $1 \%$ parasitemia. Ex-vivo ring stage survival assay $\left(\mathrm{RSA}_{\text {ex-vivo }}\right)$ was performed within 24 hours of blood collection without culture adaptation according to a previously established method ${ }^{16}$. Briefly, dilution of stock of dihydroartemisinin (DHA) $(1 \mathrm{mg} / \mathrm{mL})$ was made in a final volume of $900 \mu \mathrm{L}$ complete medium supplemented with pooled human serum, and $100 \mu \mathrm{L}$ infected erythrocyte suspension was added to test drug wells and exposed for 6 hours; each sample was cultured in triplicates. The samples were transferred to a $1.5 \mathrm{~mL}$ tube and washed twice, then maintained in culture for another 66 hours at $37^{\circ} \mathrm{C}$ using the candle jar method of Trager and Jensen ${ }^{22}$. Drug-unexposed wells for each sample served as control. The culture was terminated after 66 hours of growth and the pellet from the suspension was used to make thin smears, which were fixed in methanol and stained with Giemsa for determination of ring stage growth at $100 \mathrm{x}$ magnification by light microscopy. The proportion of viable parasites (survival) in DHA exposed/unexposed wells was expressed as a percentage. RSA $_{\text {ex-vivo }}$ values $>1$ was taken to indicate artemisinin resistance ${ }^{16,17}$.

\section{Molecular analysis}

Parasite DNA was extracted and amplified using previously published methods with primers specific for blade 6 of the $\mathrm{K} 13$ gene $^{6}$; next, $10 \mu \mathrm{L}$ of the secondary product was resolved on $2 \%$ agarose gel to confirm amplification. These condary amplicons of a few isolates were sent for sequencing at Inqaba Biotech West Africa Ltd (South Africa). The sequences were deposited in GenBank with accession numbers MH464876-464887. Polymorphisms in the parasite isolates encoding the Kelch propeller (K13) protein were compared with PF3D7_1343700 reference gene (sequence region spanning region 1,724,817$1,726,997$ bp of chromosome 13 downloaded from www.plasmoDB.org). The sequence was analyzed for molecular markers of artemisinin resistance: SNPs at codons Y493H, R539T, I543T, and C580Y, and any mutations of the gene (using Geneious software version 11.6.1). The data are reported as mean \pm standard deviation, 95\% confidence interval (CI) for continuous data; $\mathrm{P}$-value of $<0.05$ indicates a significant difference.

\section{RESULTS}

During the study period, a parasite prevalence of 40.2\% (151 had detectable parasitemia) was recorded from the cohort of 375 individuals tested for malaria infection. From this population, 55 positive samples meeting the inclusion criteria were cultured to evaluate the ex-vivo response of $P$. falciparum to DHA. At baseline, the geometric mean parasitemia in the 55 samples was $1800 / \mu \mathrm{L}$ blood [95\% confidence interval: $1823-2974 / \mu \mathrm{L}$ blood]. The mean age \pm SEM was $9.82 \pm 1.02$ years, range [0.5 - 40 years], and 26 (47\%) of them were males.

\section{Ring stage survival rates}

The parasite growth rate in d rug unexposed control wells was significantly higher than exposed well ( $\mathrm{P}<$ 0.001 ), ranging from $14.9-96.7 \%$. The mean value of parasite ring stage survival after 6 hours of DHA exposure $\left(\mathrm{RSA}_{\text {ex-vivo }}\right)$ in the drug-exposed wells was 0.18 $\pm 0.09 \%, 95 \%$ confidence interval [0.15 -0.20\%]. Fig-

ure 1 shows the distribution of individual $\mathrm{RSA}_{e x}$ vivo values obtained after exposure to $700 \mathrm{nM}$ DHA. One parasite isolate had a high $\mathrm{RSA}_{\text {ex-vivo }}$ value of $0.8 \%$. The amplified K13 gene from this isolate (C5) and other randomly selected samples are shown in Figure 2, with gene size of 849 bp. 


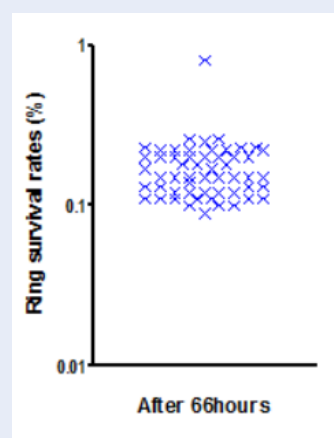

Figure 1: Ex-vivo ring stage survival (RSA $e x-v i v o$ ) of $\boldsymbol{P}$. falciparum to dihydroartemisinin in parasite isolates.

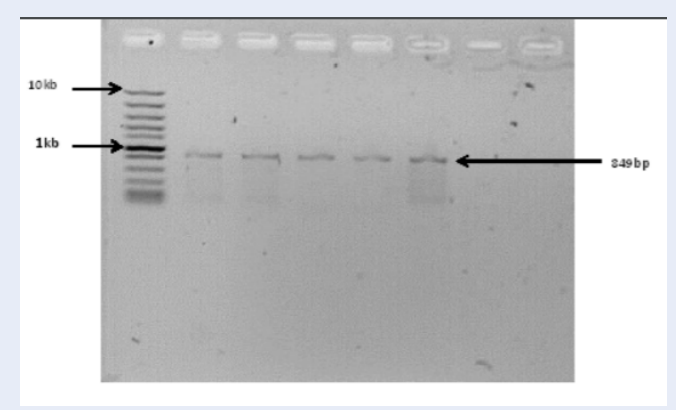

Figure 2: Gel image of $P$. falciparum Kelch propeller gene (849bp) amplification in selected isolates.

\section{K13 gene polymorphism}

Six of the 55 (10\%) isolates were analyzed for the K13 gene polymorphism and compared with the reference 3D7 strain using the standard bi-directional sequence alignment (Figures 3A, B and $\mathrm{C}$ ). There were polymor-phisms of 2 isolates (C1 and $\mathrm{C} 11)$ on single strands of the DNA (this was taken to be reading errors and not mutations). No SNPs were observed at codons C580, Y493H, R539T, I543T, R561H or $\mathrm{N} 458 \mathrm{Y}$, all of which are validated molecular markers of artemisinin resis-tance in the Mekong Subregion, Southeast Asia ${ }^{17}$. Similarly, there were no SNPs at codon A578S and A675V, which are K13 polymorphisms reported in some African regions.

\section{DISCUSSION}

Development of resistance by $P$. falciparum to all antimalarial drugs (including artemisinin derivatives) is a major problem limiting malaria elimination globally ${ }^{17}$. In SE Asia, isolates resistant to artemisinin have developed several mutations in the Kelch propeller gene ${ }^{5,6}$. Candidate markers which confer resistance to other ACTs, such as dihydroartemisininpiperaquine $^{23}$, have been identified. Six of these markers (i.e. SNPs at codon C580Y, Y493H, R539T, I543T, R561H, and N458Y) have been validated as artemisinin resistance markers in the Greater Mekong sub-region ${ }^{17}$. However, in Africa, reduced susceptibility to artemisinin and ACTs ${ }^{24}$ and limited mutations in the Kelch 13 gene ${ }^{17,20,25-27}$ with no associated artemisinin resistance have been reported ${ }^{28-33}$.

Continuous monitoring of parasite responses to individual components of the recommended ACTs should indicate any early emergence of resistance and serve to preserve the efficiency of available anti-malarials in endemic areas. In Nigeria, studies indicate that malaria transmission is still high ${ }^{21,34}$, with recent studies from regions in Nigeria reporting high mutations in genes that modulate response to nonartemisinin drugs by $P$. falciparum ${ }^{35-37}$. Conversely, other studies have reported high in-vivo response after ACTs with parasitemia half-life $<5$ hours, and 42 -day cure rates $>90 \%{ }^{38}$. However, few studies elsewhere have recently evaluated the WHO benchmarks for artemisinin resistance using RSA value and $\mathrm{K} 13$ gene polymorphism ${ }^{17,20}$. From the mean RSA of $0.18 \%$, determined in the small parasite population evaluated in this study together with no molecular marker of resistance, it can be implied that parasites susceptible to 


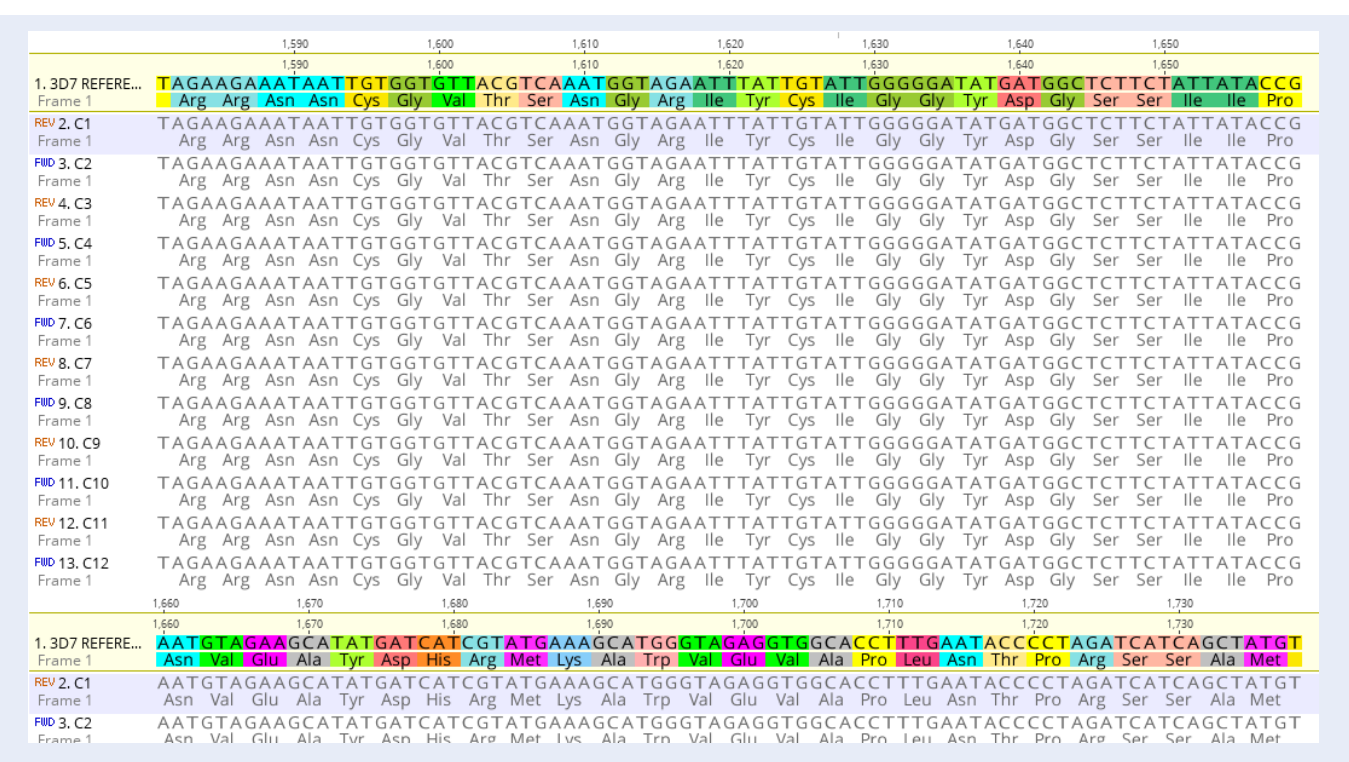

Figure 3A: Screen shot of sequence alignment of some segment of Kelch 13 gene from isolates compared with Plasmodium 3D7 sequence.

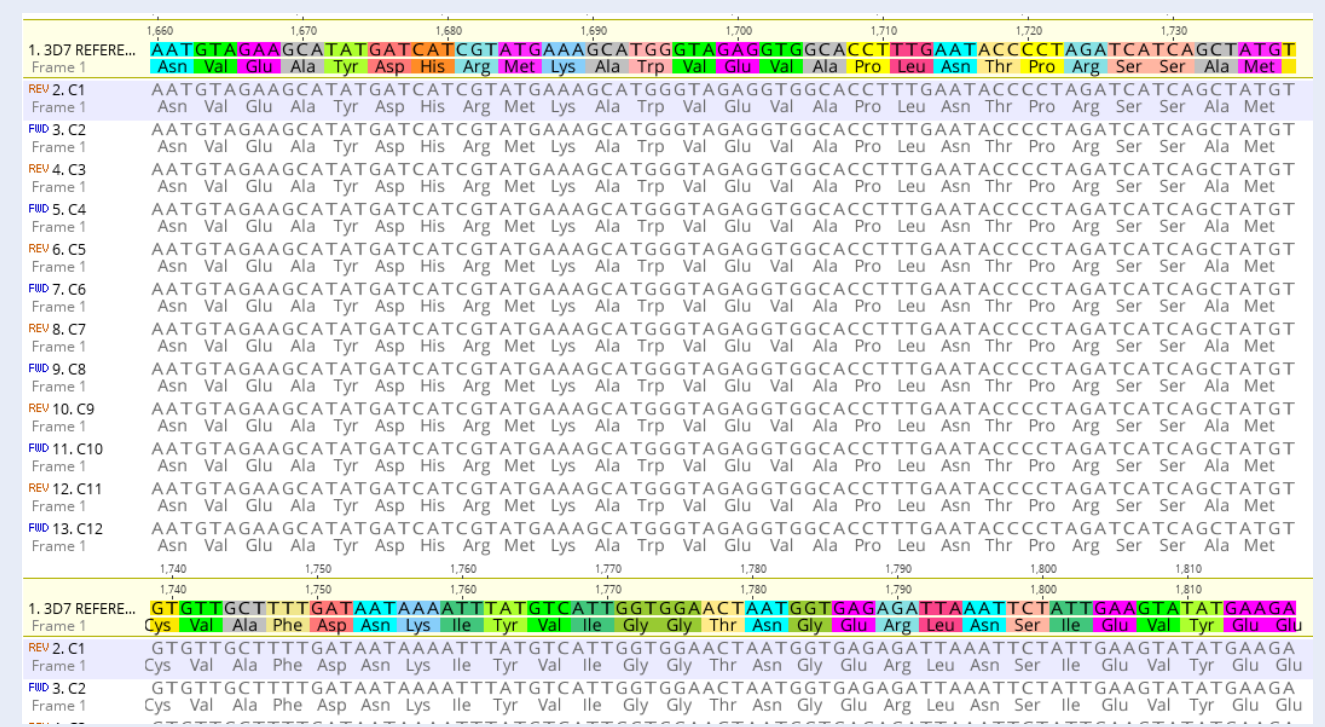

Figure 3B: Screen shot of sequence alignment of segment of Kelch 13 gene from isolates compared with Plasmodium 3D7 sequence (cont'd)

artemisinin are prevalent. Development of the ring stage survival assay for the in-vitro or ex-vivo detection of artemisinin resistance abrogates the challenge of inconsistent in-vitro results and provides a simple tool for resource-poor countries for the detection of artemisinin resistance even with small sample size ${ }^{5,6}$. The findings of the present study support previous reports of limited artemisinin resistance in Africa ${ }^{28-33}$. This, however, does not undermine the need for con- tinuous monitoring of response to artemisinin and ACTs in endemic areas to mark the beginning of declining resistance to both components of ACTs, to prevent the consequences of high morbidity and mortality in the future, and to curb the spread of artemisinin-resistant parasites to Africa where consequences will be intense $^{1}$. As part of strategies devised to contain the spread of artemisinin resistance, active monitoring of parasite responses and markers of 


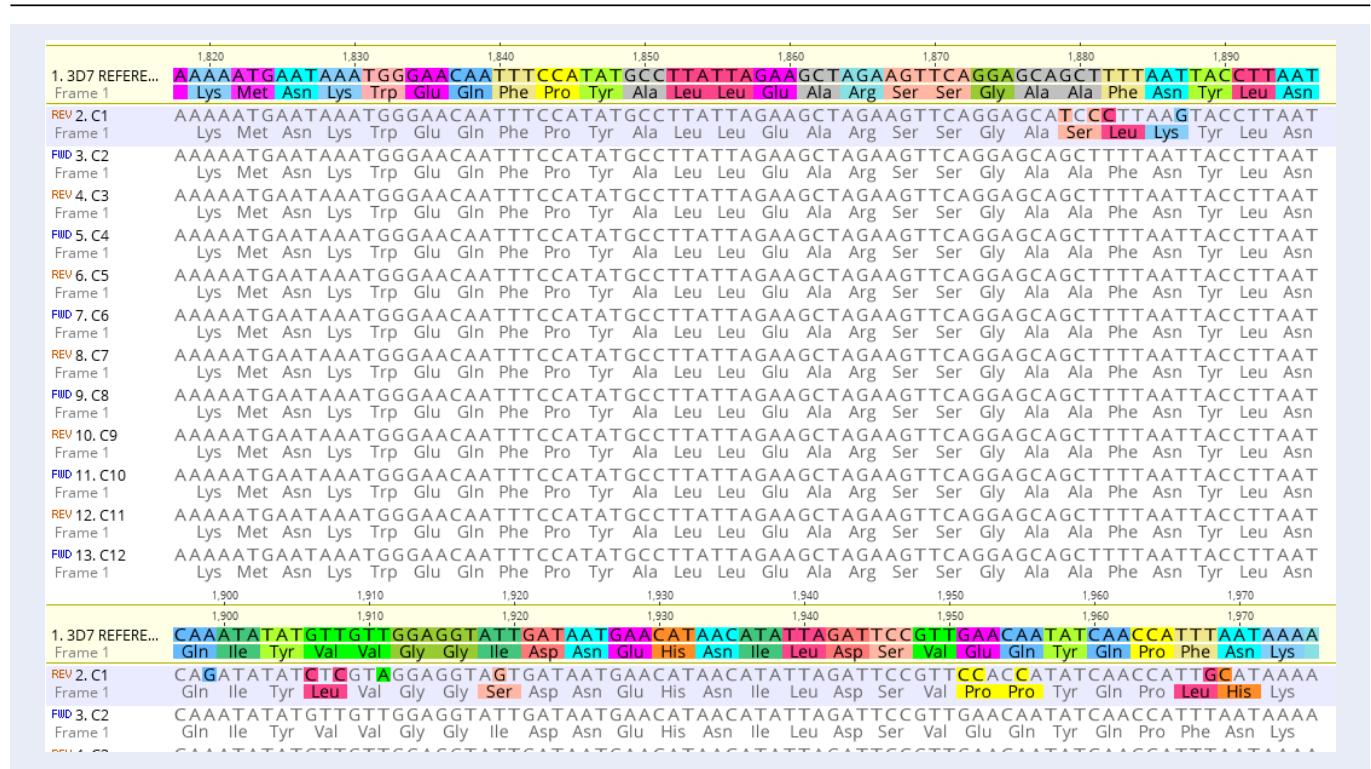

Figure 3C: Screen shot of sequence alignment of segment of Kelch 13 gene from isolates compared with Plasmodium 3D7 sequence (cont'd).

artemisinin resistance in different areas is advocated as regional differences in parasite response may exist in Nigeria ${ }^{38}$. A potential challenge will be to identify and validate resistance markers if unique markers exist in other areas. It is pertinent to monitor possible emergence in Africa from detected Kelch 13 SNP on codon A578S reported in some African countries (e.g. Kenya) ${ }^{8,25}$, M579I in China (apparently imported from Guinea, Africa) ${ }^{26}$, and A675V in Uganda ${ }^{28}$, as well as other un-validated non-synonymous SNPs ${ }^{17}$ in regions outside of Southeast Asia.

A wide range of SNPs in the K13 propeller gene developing independently from Asia, Africa and other regions ${ }^{2-8,25-33}$ calls for further research on emerging resistance and other factors that drive mutations in the malaria parasite. Furthermore, chances of emerging artemisinin resistance will increase with increasing resistance to the artemisinin drugs, as this will gradually increase drug pressure on artemisinin in endemic areas where malaria transmission is high ${ }^{21,34}$. Since clinical drug failure attributable to artemisinin has not been established, the genetic background of $P$. falciparum isolates reported in this and another study ${ }^{20}$ will aid in the early detection of mutations of the Kelch 13 domain in the parasite if artemisinin resistance develops in Nigeria. Some limitations of the current study include a small sample size of DNA that was sequenced, as well as sampling was done only in communities from one regional area (Ota, Nigeria). This may not truly represent the entire parasite population in the country.

\section{CONCLUSION}

This study reports a high susceptibility of parasites to artemisinin and no K13 polymorphism in the study area. As part of malaria elimination strategies, it is recommended that large-scale genomic studies be done routinely in the future to scale up monitoring of responses to artemisinin and its partner drugs in order to reduce the chances of development of resistance.

\section{COMPETING INTERESTS}

The authors hereby declare there are no conflicts of interest associated with this work.

\section{AUTHORS' CONTRIBUTIONS}

TMD and GIO participated in the design, conduct, analysis and writing of the manuscript; DOO, CUA, AEA, OAO, CJE, GSJ participated in the conduct and analysis of the study.

\section{ABBREVIATIONS}

ACTs: artemisinin based combination treatments DHA: Dihydroartemisinin

K13: Kelch 13 propeller gene

$\mathrm{RSA}_{(e x-v i v o)}$ : ring stage survival assay ex-vivo

\section{ACKNOWLEDGMENTS}

This research received publication funding support from Covenant University Centre for Research, Innovation and Discovery (CUCRID), Nigeria. 


\section{REFERENCES}

1. WHO. World malaria report $2017 ; 2017$.

2. Noedl $H$, Se $Y$, Schaecher $K$, Smith BL, Socheat D, Fukuda $\mathrm{MM}$, et al. Evidence of artemisinin-resistant malaria in western Cambodia. The New England Journal of Medicine. 2008;359:2619-20. Available from: DOI:10.1056/ NEJMc0805011.

3. Dondorp AM, Nosten F, Yi P, Das D, Phyo AP, Tarning J. Artemisinin resistance in Plasmodium falciparum malaria. The New England Journal of Medicine. 2009;361:455-67. Available from: DOI:10.1056/NEJMoa0808859.

4. Tun KM, Imwong M, Lwin KM, Win AA, Hlaing TM, Hlaing T. Spread of artemisinin-resistant Plasmodium falciparum in Myanmar: a cross-sectional survey of the K13 molecular marker. The Lancet Infectious Diseases. 2015;15:415-21. Available from: Doi:10.1016/s1473-3099(15)70032-0.

5. Ashley EA, Dhorda M, Fairhurst RM, Amaratunga C, Lim P, Suon $S$, et al. Spread of artemisinin resistance in Plasmodium falciparum malaria. The New England Journal of Medicine. 2014;371:411-23. Available from: DOI:10.1056/ NEJMoa1314981.

6. Ariey F, Witkowski B, Amaratunga C, Beghain J, Langlois AC Khim N. A molecular marker of artemisinin-resistant Plasmodium falciparum malaria. Nature. 2014;505:50-5. Available from: DOI:10.1038/nature12876.

7. Phyo AP, Nkhoma S, Stepniewska K, Ashley EA, Nair S, McGready R. Emergence of artemisinin-resistant malaria on the western border of Thailand: a longitudinal study. Lancet. 2012;379:1960-6. Available from: Doi:10.1016/s01406736(12)60484-x.

8. Ménard D, Khim N, Beghain J, Adegnika AA, Shafiul-Alam M, Amodu O. A Worldwide Map of Plasmodium falciparum K13-Propeller Polymorphisms. The New England Journal of Medicine. 2016;374:2453-64. null. Available from: DOI:10. 1056/NEJMoa1513137.

9. Imwong M, Suwannasin K, Kunasol C, Sutawong K, Mayxay $M$, Rekol $H$. The spread of artemisinin-resistant Plasmodium falciparum in the Greater Mekong subregion: a molecular epidemiology observational study. The Lancet Infectious Diseases. 2017;17:491-7. Available from: Doi:10.1016/s14733099(17)30048-8.

10. Straimer J, Gnädig NF, Witkowski B, Amaratunga C, Duru V, Ramadani AP. Drug resistance. K13-propeller mutations confer artemisinin resistance in Plasmodium falciparum clinical isolates. Science. 2015;347:428-31. Available from: DOI: $10.1126 /$ science.1260867.

11. Kyaw MP, Nyunt MH, Chit K, Aye MM, Aye KH, Aye MM. Reduced susceptibility of Plasmodium falciparum to artesunate in southern Myanmar. PLoS One. 2013;8:e57689. Available from: DOI:10.1371/journal.pone.0057689.

12. Witkowski B, Khim N, Chim P, Kim S, Ke S, Kloeung N. Reduced artemisinin susceptibility of Plasmodium falciparum ring stages in western Cambodia. Antimicrobial Agents and Chemotherapy. 2013;57:914-23. Available from: Doi:10.1128/ aac.01868-12.

13. Teuscher F, Gatton ML, Chen N, Peters J, Kyle DE, Cheng Q. Artemisinin-induced dormancy in plasmodium falciparum: duration, recovery rates, and implications in treatment failure. The Journal of Infectious Diseases. 2010;202:1362-8. Available from: Doi:10.1086/656476.

14. Witkowski B, Lelièvre J, Barragán MJ, Laurent V, Su XZ, Berry A. Increased tolerance to artemisinin in Plasmodium falciparum is mediated by a quiescence mechanism. Antimicrobial Agents and Chemotherapy. 2010;54:1872-7. Available from: Doi:10.1128/aac.01636-09.

15. Amaratunga $C$, Sreng $S$, Suon $S$, Phelps ES, Stepniewska $K_{\text {, }}$ Lim P. Artemisinin-resistant Plasmodium falciparum in Pursat province, western Cambodia: a parasite clearance rate study. The Lancet Infectious Diseases. 2012;12:851-8. Available from: Doi:10.1016/s1473-3099(12)70181-0.

16. Network WAR. Ring-stage Survival Assays (RSA) to evaluate the in-vitro and ex-vivo susceptibility of Plasmodium falciparum to artemisinins. 2015.

17. WHO. Status report on artemisinin and ACT resistance; 2017.

18. Bustamante C, Folarin OA, Gbotosho GO, Batista CN Mesquita EA, Brindeiro RM. In vitro-reduced susceptibility to artemether in P. falciparum and its association with polymorphisms on transporter genes. The Journa of Infectious Diseases. 2012;206:324-32. Available from: DOI:10.1093/infdis/jis359.

19. Oduola AM, Sowunmi A, Milhous WK, Kyle DE, Martin RK, Walker $O$. Innate resistance to new antimalarial drugs in Plasmodium falciparum from Nigeria. Transactions of the Royal Society of Tropical Medicine and Hygiene. 1992;86:1236. Available from: Doi:10.1016/0035-9203(92)90533-i.

20. Kamau E, Campino S, Amenga-Etego L, Drury E, Ishengoma D, Johnson K. K13-propeller polymorphisms in Plasmodium falciparum parasites from sub-Saharan Africa. African Journal of Infectious Diseases. 2015;211:1352-5.

21. Dokunmu TM, Olasehinde GI, Oladejo DO, Olanrewaju O, Akinbobola A, Adjekukor CU. Efficiency of histidine rich protein II-based rapid diagnostic tests for monitoring malaria transmission intensities in an endemic area. AIP Conference Proceedings. 2018;1954:030001. Available from: Doi:10.1063/1. 5033381.

22. Trager W, Jenson JB. Cultivation of malarial parasites. Nature. 1978;273:621-2. Available from: DOI:10.1038/273621a0.

23. Amato R, Lim $P$, Miotto $O$, Amaratunga $C$, Dek D, Pearson RD. Genetic markers associated with dihydroartemisininpiperaquine failure in Plasmodium falciparum malaria in Cambodia: a genotype-phenotype association study. The Lancet Infectious Diseases. 2017;17:164-73. Available from: Doi:10. 1016/s1473-3099(16)30409-1.

24. Borrmann S, Sasi P, Mwai L, Bashraheil M, Abdallah A, Muriithi $S$. Declining responsiveness of Plasmodium falciparum infections to artemisinin-based combination treatments on the Kenyan coast. PLoS One. 2011;6:e26005. Available from: DOI:10.1371/journal.pone.0026005.

25. de Laurent ZR, Chebon LJ, Ingasia LA, Akala HM, Andagalu B, Ochola-Oyier LI. Polymorphisms in the K13 gene in Plasmodium falciparum from different malaria transmission areas of Kenya. The American Journal of Tropical Medicine and Hygiene. 2018;98:1360-6. Available from: DOI:10.4269/ajtmh. 17-0505.

26. Lu F, Culleton R, Zhang M, Ramaprasad A, von Seidlein L, Zhou $\mathrm{H}$. Emergence of indigenous artemisinin-resistant Plasmodium falciparum in Africa. The New England Journal of Medicine. 2017;376:991-3. Available from: DOI:10.1056/ NEJMc1612765.

27. Li J, Chen J, Xie D, Eyi UM, Matesa RA, Obono MMO. Limited artemisinin resistance-associated polymorphisms in Plasmodium falciparum K13-propeller and PfATPase6 gene isolated from Bioko Island, Equatorial Guinea. International Journal for Parasitology Drugs and Drug Resistance. 2016;6:54-9. Available from: DOI:10.1016/j.ijpddr.2015.11.002.

28. Ikeda M, Kaneko M, Tachibana SI, Balikagala B, SakuraiYatsushiro M, Yatsushiro S. artemisinin-resistant Plasmodium falciparum with high survival rates, Uganda, 2014-2016. Emerging Infectious Diseases. 2018;24:718-26. Available from: DOI:10.3201/eid2404.170141.

29. Taylor SM, Parobek CM, DeConti DK, Kayentao K, Coulibaly SO, Greenwood BM. Absence of putative artemisinin resistance mutations among Plasmodium falciparum in SubSaharan Africa: a molecular epidemiologic study. The Journal of Infectious Diseases. 2015;211:680-8. Available from: DOI:10.1093/infdis/jiu467.

30. Torrentino-Madamet M, Fall B, Benoit N, Camara C, Amalvict $\mathrm{R}$, Fall M. Limited polymorphisms in $\mathrm{k} 13$ gene in Plasmodium falciparum isolates from Dakar, Senegal in 2012-2013. Malaria Journal. 2014;13:472. Available from: Doi:10.1186/1475-287513-472.

31. Heuchert A, Abduselam N, Zeynudin A, Eshetu T, Löscher T, 
Wieser A. Molecular markers of anti-malarial drug resistance in southwest Ethiopia over time: regional surveillance from 2006 to 2013. Malaria Journal. 2015;14:208. Available from: DOI:10.1186/s12936-015-0723-2.

32. Escobar C, Pateira S, Lobo E, Lobo L, Teodosio R, Dias F, et al. Polymorphisms in Plasmodium falciparum K13-propeller in Angola and Mozambique after the introduction of the ACTs. PLoS One. 2015;10(3):e0119215.

33. Conrad MD, Bigira V, Kapisi J, Muhindo M, Kamya MR, Havlir DV. Polymorphisms in K13 and falcipain-2 associated with artemisinin resistance are not prevalent in Plasmodium falciparum isolated from Ugandan children. PLoS One. 2014;9:e105690. Available from: DOI:10.1371/journal.pone. 0105690 .

34. Olasehinde Gl, Ojurongbe DO, Akinjogunla OJ, Egwari LO, Adeyeba AO. Prevalence of malaria and predisposing factors to antimalarial drug resistance in southwestern Nigeria. Research Journal of Parasitology. 2015;10:92-101. Available from: DOI:10.3923/jp.2015.92.101.

35. Muhammad RH, Nock IH, Ndams IS, George JB, Deeni Y. Distribution of pfmdr1 and pfcrt chloroquine drug resistance alleles in north-western Nigeria. MalariaWorld Journal. 2017;8:15.

36. Oladipo OO, Wellington OA, Sutherland $\mathrm{CJ}$. Persistence of chloroquine-resistant haplotypes of Plasmodium falciparum in children with uncomplicated Malaria in Lagos, Nigeria, four years after change of chloroquine as first-line antimalarial medicine. Diagnostic Pathology. 2015;10:41. Available from: DOI:10.1186/s13000-015-0276-2.

37. Gbotosho GO, Sowunmi A, Happi CT, Okuboyejo TM. Therapeutic efficacies of artemisinin-based combination therapies in Nigerian children with uncomplicated falciparum malaria during five years of adoption as first-line treatments. The American Journal of Tropical Medicine and Hygiene. 2011;84:936-43. Available from: DOI:10.4269/ajtmh.2011.100722 .

38. Oguche S, Okafor HU, Watila I, Meremikwu M, Agomo P, Ogala W. Efficacy of artemisinin-based combination treatments of uncomplicated falciparum malaria in under-five-year-old Nigerian children. The American Journal of Tropical Medicine and Hygiene. 2014;91:925-35. Available from: DOI:10.4269/ ajtmh.13-0248.

\section{Scan to download the article}

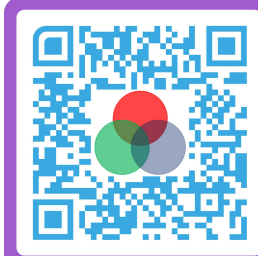

Scan me 